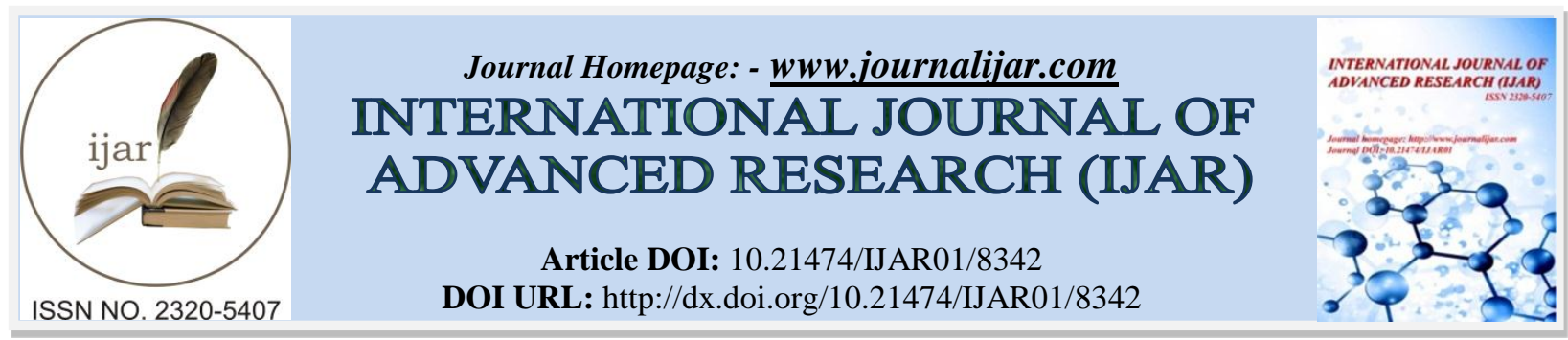

RESEARCH ARTICLE

\title{
DISRUPTIVE TECHNOLOGIES AND MANAGEMENT OF THE TALENT ECO-SYSTEM IN NIGERIA.
}

\author{
Abel Aig. ASEIN ${ }^{1}$, O. Makinde ${ }^{2}$ and Olalekan U. Asikhia ${ }^{2}$. \\ 1. Department of Accounting, Babcock University, Ilisan, Ogun State, Nigeria. \\ 2. Department of Business Administration, Babcock University, Ilisan, Ogun State, Nigeria.
}

\section{Manuscript Info}

Manuscript History

Received: 08 November 2018

Final Accepted: 10 December 2018

Published: January 2019

Key words:-

Talent Eco-system, Artificial Intelligence, Robotics, Digital employee, learning machine.

\begin{abstract}
Globally, disruptive technology is redefining workplace personnel, displacing poorly skilled employees and replacing them with digital employees with significant implications for skills gap and talent ecosystem. Organisations that decline to change will lose not only competitive advantage but become irrelevant and an unattractive place for digitally inclined employees to make careers. Accordingly, human resource management practice in Nigeria must change its existing model to address the emerging issues of talent management, career paths, reskilling, the composition of workplace employees, ergonomics and the human side of enterprise.
\end{abstract}

Copy Right, IJAR, 2019,.All rights reserved.

\section{Introduction:-}

Organisations are often set up to achieve diverse goals driven by the persuasion and motivating objectives of their founders. Therefore, some organisations may be set up to produce goods and services with a view to maximizing profit as in the case of listed companies while some may be established in the form of non-governmental organisations (NGOs) to carry out charity-related works for the benefit of society. Some others may also be set up by the government to deliver welfare services to the citizens. Lately, the purpose of business has been expanded to include corporate social responsibility and sustainability of the environment (Brundtland, 1987). What is common with these variants of organisation is that they are entities which comprise people, working for collective goals and managed by an apex authority which provides resources and direction. Despite the fact that its membership of organisation is not permanent, the ways that people are attracted, recruited, engaged and deployed are structured to achieve the long term purpose of the entity. Their job description often contains the values and contributions that potential employees are expected to bring to the table even as they strive to adapt to the cultural practices of the entity.

Many annual reports by board chairmen of listed corporate entities in Nigeria often claim that the employees so engaged are their most important assets and the secret of their success (See audited annual reports of UBA PLC for 2015, 2016 and 20171; Nestle PLC for 2015, 2016 and 2017). A visit to the corporate headquarters or shop floor of any of these entities at the close of business will affirm that the employees give life to the workplace. However, this phenomenon is changing with the $4^{\text {th }}$ Industrial Revolution which entails automation and the use of artificial intelligence, machine learning and robots which are collectively regarded as disruptive technology. With disruptive technology, the outlook of the work environment globally, is changing very rapidly. Digital employees may become the most prized asset.

Corresponding Author:-Abel aig. Asein.

Address:-Department of Accounting, Babcock University, Ilisan, Ogun State, Nigeria. 
McKinsey (2017) reports that between 39million and 73million jobs will be automated in USA while globally, an estimated 800million jobs will be lost to automation by 2030. According to the report, nations will be differently affected based on their level of average wages, amongst other factors. Economies with high average wages like USA and Germany will have the incentive to automate and reduce cost. African nations with poor average wages may take some time to embrace disruptive technology and experience the impact. Although they are closer to it than they ever thought considering the achievements recorded with ecommerce in Nigeria, this view is reinforced by the fact that resources to deploy such disruptive technology are not readily available. For proactive nations, this is the time to prepare for the unknown and uncertain future, rather than stall.

The World Economic Forum(2016) in its Future of Jobs Report observed that about 5.1million jobs will be lost to disruptive labour market over the period 2015-2020 and that about 7.1million jobs(two-thirds of which are concentrated on white collar office jobs) will be lost. According to Kapoor (2011,p.1),

"the global supply of talent is short of its long-term demand, and the gap is a challenge for employers everywhere. The shortage between the demand and supply of talent is likely to continue to increase, notably for high skilled workers and for the next generation of business executives. Now organizations need to place greater emphasis on attracting human capital rather than financial capital".

A report by PEBEC (2018), that is, the Nigeria's Presidential Enabling Business Environment Council, shows that more and more organisations are automating their processes and deploying various kinds of software to deliver online, real time, qualitative services to the clients in the country. The capacity and efficiency of software are far above what humans can deliver. Increasingly therefore, organisations are experiencing lean management particularly in terms of employment of humans. For instance, with enhanced computer skills by managers in Nigeria, only few organisations still have secretaries today in the country. The Institute of Chartered Accountants of Nigeria and the Big 4 firms no longer have secretaries. The same trend applies to many listed entities and deposit money banks in Nigeria. Managers are now their own secretaries while many run their offices from hand held smart phones with diverse applications. With the increasing use of technology by corporate entities in quest for efficiency and more profit, the culture of working from home is gradually gaining acceptance in the country. The Automated Teller Machines have taken over a lot of jobs on the shop floors of banks in addition to increasing the banking hours to 24hours, seven days a week.

Deloitte (2018) predicts that the next five years could be significant for many organisations in Nigeria as the professional environment becomes almost overwhelmed by rapid change driven by technology. Digital-based reforms, according to the report, will intensify in tax administration in order to block leakages. The implication will be less human intervention and fewer hands will be engaged. With Internet users in the country estimated at 94million by Nigerian Communications Commission (NCC) in the first quarter of 2018, the Federal Government of Nigeria itself has embraced eGovernance and commenced the automation of its processes (Shittu, 2018).

Although the study by McKinsey Global Institute (2017) holds that technology will destroy jobs but not eliminate work, the fear is rife that humans will lose all repetitive jobs to automation in the quest for efficiency and profit by 2030. In essence, with the purchase and deployment of artificial intelligence, robots and learning machines, most repetitive tasks performed by some employees will not only be taken over but also, humans will have new work colleagues in the form of machines and robots. In other words, automation of repetitive jobs will result in excellent outcomes but loss of jobs and wages by unskilled persons, diminution in tax revenues from incomes and possible fiscal challenges for various governments. More importantly and this is the concern and thrust of this paper, the replacement of humans with machines has implications for human resource management practices including the talent ecosystem, talent management, the composition of workplace employees, ergonomics and the human side of enterprise. Employees of the 4th Industrial Revolution will be faced with the prospects of having digital colleagues who are robots! Such a scenario would impact the talent eco-system, the practice of human resource management, its value propositions and the skillset of employees in affected corporate entities. How these emerging challenges are addressed would be the acid test for human resource management as a critical success factor in the evolving era of disruptive technology for many organisations.

This paper is segmented into five parts including the introductory section. Part two is a review of the literature while part three contains the methodology. The fourth section discusses human resource management activities in an era of disruptive technology in Nigeria. The fifth contains the conclusion and recommendation. 


\section{Literature review \\ Conceptual review Organisation}

In simple terms, an organisation refers to a structured entity or coordinated whole that has interdependent and interactive parts. It can also be seen as an entity comprising people, such as an institution or an association, that has a collective goal and is linked to an external environment. Organisations do not live in a vacuum neither do they operate in a closed system but interact with and impact the environment where they subsist. In other words, it is a social unit of people that is structured to meet some needs or pursue collective goals in a given environment with defined boundaries. Pursuant to this, all organisations have a management structure that determines relationships between the different activities and the members, subdivides and assigns roles as well as responsibilities. Over the years, most of these functions are carried out by people with diverse socialisation and competences. The formation of organisations is driven by the persuasive philosophy that people can achieve much more in groups than when they work individually. In other words, organisations are driven by the possibility of synergy through human collaboration. This virtue is reinforced by the fact that the existence of organisations often lead to a reduction in transaction costs as things can be done in-house instead of with outsiders or third parties.

\section{Workplace Diversity}

This refers to the characteristics or nature of employees engaged by an entity. The beauty of the workplace is reflected in the diversity of its employees based on gender, race, ethnicity, socialisation and skillset. Although it negatively affects team building, workplace diversity enhances the quality of decisions taken and eliminates narrow perspective. Indeed, employees are often engaged because they have undergone different socialization processes, education and exposure and have diverse beliefs and orientation as well as personality traits. Since the lack of work diversity will lead to a narrow perspective of issues, stale corporate and cultural practices; and a tendency to live with the status quo for too long, many organisations have embraced diversity as a strategy to drive their growth by fostering the expansion of differing ideas and viewpoints while ensuring a sufficiently cohesive environment that efficiently gets things done.

\section{Talent Eco-System}

This refers to the various skills and expertise of employees on the basis of which they were employed, deployed, assigned responsibilities and how they complement each other. The diverse skills and competences of employees are expected to reinforce, and not compete, with each other in order to drive corporate success. This is the thrust of talent eco-system which is geared towards optimising the output from the entity's human resource as a collective.

\section{Artificial Intelligence}

Artificial intelligence (AI) describes a machine or software that can demonstrate behaviours which are similar to that of the human brain. Human beings learn, reason and correct themselves when errors are made. Software or machine that can carry out these three functions are described as artificial intelligence. With artificial intelligence, a machine or software can carry out repetitive human tasks. AI is about intelligently imitating human behaviours.

\section{Robotics}

These are man-made and programmed machines that can carry-out instructions and execute tasks of repetitive nature. They are the emerging new colleagues of humans in the workplace. As robotics evolves and converges with other emerging technologies, a new world of workplace operational possibilities and rules of engagement will emerge.

\section{Machine learning}

This refers to the science of getting computers to learn and act like humans do and improve their learning over time in autonomous fashion, by feeding them data and information in the form of observations and real-world interactions. In other words, an un-programmed machine is thought to think, learn and act like humans.

\section{Human resource management:}

This involves all the processes for recruiting, engaging, deploying, training, assigning responsibilities, rewarding and disengaging employees. It also deals with the issues of talent and talent ecosystem management. 


\section{Theoretical Background}

One key characteristic of organisation is that work is compartmentalised such that the output of one unit is the input of the other. Working in and as a system, employees enjoy the benefits of division of labour and synergy of collaboration. Developed by Hergenhahn (1976) as cited by Benecke, Schurink, and Roodt (2007), the Theory of Synergy holds that the whole is more than the sum of its parts. When individuals work together, they have the capacity to create more value. According to Gupta and Roos (2001, p.298), synergy is "the interaction of two or more intellectual capital resources from previously sovereign organisations, which enhances the combined effect of value creation and competitive performance which effect is greater than the sum of the individual effects".

Synergy is a concept that describes the systemic processes whereby business units of diverse complex organisations will generate greater value through working as one system than working as separate entities. With unskilled labour handling repetitive tasks being replaced by technology, there will be synergy in the form of increased output and reduced costs. The precision and speed of machines will reinforce the creativity of skilled employees to impact productivity. It is in this sense that the Theory of Synergy is reinforced by the Theory of Efficiency in the use of resources and the maximisation of output from given inputs.

Expectedly, with the acquisition and deployment of diverse software, artificial intelligence and robots, more humans will be displaced by digital labour implying that the human resource function must proactively plan how to deal with the associated issues of the redefinition and redesign of roles and responsibility, retraining, redeployment, performance management, emotional intelligence, management of idle (redundant) hands, downsizing, cost of layoffs, exit and exit-interviews. Shifting of focus from hard skills to soft skills will become imperative for survival. Here lies the relevance of sustainability theory in talent management.

According to iXerv (2016), sustainability in talent management context is about organisations developing their future leaders, managers, specialists and employees from the talent potential within. This entails, identifying, developing and promoting existing employees with the right values, change-oriented mindset such that they can rise to fill the gaps being created by disruptive technology. Sustainability theory of talent management is particularly important here because there is no unlimited supply of skilled labour outside the organisation to be explored unend. Given the competition for skilled labour, organisations must learn to reduce their dependence on external supply of skilled human capital. They should learn to reduce the tendency to hire externally by striving to release the potential of individuals in the organisation through training and assignment of responsibilities coupled with authority. It is not only cheaper but less disruptive.

\section{Methodology:-}

This study, which relies significantly on ex-post facto secondary information, adopted a qualitative content analysis methodology to examine the nature of human resource activities in an era of disruptive technology in Nigeria. This approach was chosen because how human resource management practices are carried out has implications for the ability of human capital to define and drive the other inputs in the process of value creation. Irrespective of the technology deployed, how well the human resource management function is performed in this era, will determine the survival, growth, prosperity and sustainability of the corporate entity.

\section{Human Resource Management Activities in an Era Disruptive Technology}

The fundamental roles of human resource management are to attract, retain, deploy and develop talent to meet current and future business needs (Mercer, 2018). With these responsibilities, the human resource department is generally perceived and treated as a cost centre. However, the environment for carrying out these functions have been impacted both by disruptive technology and the movement metrics of employees seeking better environment for self-fulfilment. As a result, human resource management is assuming more importance than it previously did in strategic planning and board charter. Its emphasis is now on long term sustainability of talent rather than short term savings and efficiency (Kapoor, 2011).

The era of disruptive technology involves the automation of processes and the replacement of the factor of unskilled man who does repetitive manual tasks, with technology. The shop floor will now increasingly be dominated by robots and machine learning with possible negative impact on the nature and content of the talent eco-system. Given the precision and speed of machines or the digital labour, who are the physical employees of the future? What will be their attributes? What would be their success DNA or performance indicators? Would the human creativity of 
skilled employees still be sufficient to continue to lead projects and even entire businesses? Would technology remain business enablers or agents of job destroyers?

With this scenario and as the above question beg for answers from diverse stakeholders, it is safe to wager that the human resource management function of recruitment of this special category of unskilled employees will diminish in importance while the issue of re-skilling of remaining staff in the new environment will receive premium attention in Nigeria and in many jurisdictions. Given the rapidity of these changes, human resource practitioners may need to consider whether to build their own or hire talent based on their knowledge of what drives labour turnover in their various organisations. Considering the high cost of new hires, sustainability of talent management is crucial and inevitable. This would involve building human capacity from the people already engaged. Thus, human resource department must carry out talent analytics to determine what drives high performing teams and the type of training that is most effective for their own people (Mercer, 2018). It will need to undertake comprehensive appraisal of the competences of existing staff, determine the skills gap and how to train and/or fill specialist skills gap through headhunting or similar approaches. Based on the strategic direction of the enterprise, the human resource department will need to design a skill requirement map that will drive human resource activities all through the entity over the longer term.

Given the rapidity of technological changes, management of the skills gap will increasingly become more challenging as the talent-ecosystem is altered. Organisations that do not pro-act may become victims of the inevitable change. According to Kapoor (2011, p.1), "Companies with the ability to foresee their business needs and their workforce needs-especially for high skills-will gain the decisive competitive advantage". This line of thought was shared by KPMG (2018), when it asserted that,

"while many organisations are evaluating or implementing automation, few organisations are sufficiently retooling their talent strategies to keep up. As robotics moves beyond early adopter phase, the pace of change will accelerate, leaving unprepared organisations behind. This fast-changing talent landscape requires companies to update their talent strategies to align to the business strategy including digital strategy, since most talent strategies are rooted in a pre-digital human resource model, update talent strategies that embrace intelligent automation and robotics set the foundation for a successful talent ecosystem (p.2).”

Addressing the skills gap that will increasingly become more pronounced in the months ahead through external recruitment is neither sufficient nor strategically appropriate since skilled labour out there is limited in supply. Skills shortages occur when the labor market does not produce enough qualified candidates to fill the needed number of positions within a particular occupation. This can be due either to a lack of required skills, work experience, or educational qualifications or credentials. Skills gap may also occur where, for a variety of reasons, existing employees within an organization do not have the needed skills to perform new or additional tasks within their current or future job roles. A recent study attributed the high rate of employment among university graduates in Nigeria to this skills gap or mismatch between output of the university system and marketplace skills requirements (Longe, 2017, Okafor, 2011). This difficulty in securing skilled personnel for employment is not peculiar to Nigeria. Consider the following findings of the global Society for Human Resource Management in USA in 2016.

Table 1 is Society for Human Resource Management (SHRM) Leading Indicators of National Employment (LINE) Recruiting Difficulty Index for 2016 in USA.

"The SHRM LINE Report examines four key areas: employers' hiring expectations, new-hire compensation, recruiting difficulty and job vacancies. It is based on a monthly survey of private-sector human resource professionals at more than 500 manufacturing and 500 service-sector companies. Together, these two sectors employ more than $90 \%$ of the nation's private-sector workers. LINE's recruiting difficulty index measures how difficult it is for firms to recruit candidates to fill the positions of greatest strategic importance to their companies. The recruiting difficulty index shows that in both manufacturing and services, HR professionals are experiencing difficulty finding applicants for these jobs at levels not seen since before the Great Recession of 2007-2009(SHRM, 2016, P.10)".

Table 1:-Reasons Organizations Have Difficulty Hiring For Full-Time Regular Positions

- Low number of applicants

- Candidates do not have the needed work experience $51 \%$ $\mathbf{5 0 \%}$ 


\begin{tabular}{|c|c|}
\hline - Competition from other employers & $49 \%$ \\
\hline - Candidates do not have the right technical skills & $38 \%$ \\
\hline - The local market is not producing enough work-ready/qualified job candidates & $38 \%$ \\
\hline - Salaries are not competitive for the market & $34 \%$ \\
\hline $\begin{array}{l}\text { - Candidates do not have the right workplace (soft) skills (problem-solving, interpersonal } \\
\text { skills, communication, teamwork, leadership, etc.) }\end{array}$ & $30 \%$ \\
\hline - Qualified candidates are not interested in moving to our local area & $26 \%$ \\
\hline - Candidates do not have the needed credentials/certifications & $24 \%$ \\
\hline - Candidates reject compensation package & $23 \%$ \\
\hline - Lack of interest in type of job among job seekers & $17 \%$ \\
\hline - Candidates do not have the needed training & $16 \%$ \\
\hline - Candidates do not have high enough levels of education & $11 \%$ \\
\hline $\begin{array}{l}\text { - Candidates do not have the right basic skills (reading, writing, math, basic computer skills, } \\
\text { etc.) }\end{array}$ & $11 \%$ \\
\hline - Candidates are overqualified & $10 \%$ \\
\hline - Qualified candidates are not able to move to our local area (due to mortgage or other issues) & $9 \%$ \\
\hline - Relocation package is not competitive or not provided & $\mathbf{8 \%}$ \\
\hline - Candidates reject benefits package & $6 \%$ \\
\hline
\end{tabular}

Source: SHRM Leading Indicators of National Employment (LINE) historical data

From Table 1 above, as high as $38 \%$ of applicants do not have the technical skills required for employment. The same 38\% applies to mismatch between workplace requirements and the output of the education system while competition from other employers account for $49 \%$. These point to the need for talent ecosystem management as a strategy to address this skills gap. In view of this, organisations must develop their talent management model, redefine career paths of employees and invest in talent management as competitive advantage.

Indeed, one critical function that the human resource management must put on the front burner is that of talent ecosystem and how to manage it. The talent ecosystem refers to how the diverse skills and competences of employees support and reinforce themselves. In an era of disruptive technology, human resource managers must be aware of the talent ecosystem and how it can meet their needs. They need to retain and develop the people they have, occasionally hire new talent to keep their propositions fresh. Motivation is also very important particularly when the entity handsomely rewards its employees.

In line with findings of the Elton Mayo's Hawthorne study, there is need to cater to the social psychological needs of employees, beyond financial and economic rewards, to keep them in employment. This will encourage them to buy into the corporate vision. To maintain their competitive advantage, human resource managers must strategically decide, as matter of corporate policy, to hire employees based on skills, competences and merits, find and retain the right talent, reward and motivate them. This is important because, as AI and robotics shape the future of work, only people can unlock the value of technology investments. Without a bold culture of innovation and lifelong learning, organizations will fall behind (Mercer, 2018). Employees that are retained would move on to higher value oriented activities of advisory and decision making. "Shifting to higher value work like strategy and analytics, from repetitive, manual tasks will be essential to remain relevant in the marketplace (KPMG, 2018, p.8)"

For employees whose competences cannot be enhanced with more training, they may be canvassed out of the organisation through an efficient and effective disengagement management system. This is very important if the organisation desires that its previous employees will be and remain its ambassadors. When employees exit an organisation with happiness, the organisation is saved the cost of information management.

There is also the need to build trust amongst the existing personnel. With every automation plan comes suspicion of job losses by employees. It is imperative to reassure them of job security through strategic mind-set change. Indeed, better results will be achieved if they are consulted and their views obtained on important strategic issues before a final decision is taken. If employees own the initiative, they will drive it to success. 


\section{Conclusion:-}

In every organisation, the people issue must be confronted and addressed particularly in the light of disruptive technology and its implications for skills gap and job losses. Despite the high unemployment rate, many companies struggle to find the right staff, right talent with the right skills to hire in Nigeria. Indeed, because of changing technology, businesses are struggling to find qualified workers with IT skills, data analytic competences, problem solving abilities, deductive reasoning skills and emotional intelligence. Accordingly, the human resource function in Nigeria must take on greater responsibility to manage the talent ecosystem for the sustainability of the business. The corporate strategy must seek to address, on a sustainable basis, the pipeline for the supply of the corporate leaders of tomorrow even as the number of digital personnel continues to increase. To ignore the challenge of disruptive technology in Nigeria is to treat sustainability of talent management with kid globes with severe consequences for the organisation's going concern status.

\section{References:-}

1. Archer, T.S. (2010). The Efficiency theory. Manuscript edited by Michael Aschenbach. ISBN: 1-4563-2007-6. www.theefficiencytheory.com>the_Efficiency_Theory. Retrieved on September 7, 2018

2. Argote, L., Goodman, P.S. \& Schkade, D. (1983). The human side of robotics: how workers react to a robot. Sloan Management Review, 24(3), 31-41

3. Benecke, G., Schurink, W. and Roodt, G.(2007). Torwards a substantive theory of synergy. SA Journal of Human Resource Management, 5(2), 9-19

4. Kapoor, B. (2011). Impact of Globalization on Human Resource Management. Journal of International Management Studies, 2.

5. Brandasa, C., Megana, O. \& Didragaa, O. (2013). Global perspectives on accounting information systems: mobile and cloud approach. Procedia Economics and Finance 20 (2015) 88 - 93. 7th International Conference on Globalization and Higher Education in Economics and Business Administration, GEBA.

6. Brundtland, G. H. (1987). World Commission on Environment and Development, Our common future. UK: Oxford University press.

7. Castro, M., \& Martins, N. (2010). The relationship between organisational climate and employee satisfaction in a South African information and technology organization. SA Journal of Industrial Psychology/SA TydskrifvirBedryfsielkunde, 36(1), A., 1-11.

8. Chan, L.M., Shaffer, A., Snape, E. (2004), In search of sustained competitive advantage: the impact of organizational culture, competitive strategy and human resource management practices on firm performance. International Journal of Human Resources, 15, 17-35.

9. Christensen (1997). The Innovator's Dilemma: When New Technologies Cause Great Firms to Fail. Boston, MA: Harvard Business School Press.

10. CIMA (2017). Integrated Thinking-Aligning purpose and the business model to market opportunities and sustainable performance. CIMA Research Executive Summary, July, 13(3), 4

11. Deloitte (2018). Deloitte predicts Automation Transforming Tax Administration. Thisday Newspapers, November 23. Extracted from thisdaylive.com on December 6, 2018

12. Docherty, P. (2018). Technology: A Tale of Two Practices. IFAC Global Knowledge Gate way, June 28. Retrieved on Dec 12, 2018

13. Docherty, P. (2018). Developing a Technology Strategy. IFAC Global Knowledge Gate way, May 31.Retrieved on December 12, 2018.

14. Guney, A. (2014). Role of technology in accounting and e-accounting. Procedia - Social and Behavioral Sciences, 152 (2014) $852-855$.

15. Gupta, O. and Roos, G. (2001). Mergers and acquisition through an intellectual capital perspective. Journal of Intellectual capital, 2(3), 297-309.

16. Hengenhahn, B.R. (1976). An introduction to theories of learning. New Jersey: Prentice-Hall.

17. iXerv (2016) (Ed.). Talent Management: All about sustainability. Retrieved from http://www.ixerv.com/knowledgebase/talent-management-sustainability/ on Dec 13, 2018.

18. Kok, J.N., Boers, E.J.W., Kosters, W.A., van der Putten, P. and Poel, M. (2009), Artificial Intelligence: Definition, Trends, Techniques and Cases. Encyclopaedia of Life Support System (EOLSS). http://www.eolss.net/Eolss-sampleAllChapter.aspx Accessed on December 6, 2018.

19. KPMG (2017). Living with robots. KPMG Future of Work series. Retrieved from kpmg.com/us/FutureOfWork on December 12, 2018 
20. Lim, F.P.C (2013). Impact of Information Technology on Accounting Systems. Asia-pacific Journal of Multimedia Services Convergent with Art, Humanities, and Sociology, 3(2), December, pp. 93-106. http://dx.doi.org/10.14257/AJMAHS.2013.12.02

21. Lindsay, C., Findlay, P., Mcquarrie, J., (2017). Collaborative Innovation, New Technologies, and Work Design. Public Administration Review, September 7. Wiley Online Library. https://doi.org/10.1111/puar.12843

22. Longe, O. (2017). Graduate Unemployment in Nigeria: Causes, Consequences and Remediable Approaches. American International Journal of Contemporary Research, 7(4), December, pp.63-73.

23. McKinsey Global Institute (2017). Jobs lost, jobs gained: Workforce Transitions in a time of automation. $\begin{array}{lllll}\text { Retrieved } \quad \text { on } & \text { December } & 12, & 2018\end{array}$ https://www.mckinsey.com/ /media/Mckinsey/Global/themes/futureoforganisation/whatthefutureofworkwillme anforjobsskillsandwages/MGI-Jobs-Gained-Report-December-6-2017.ashx

24. Mercer (2018). Global talent trends study-unlocking growth in the human age

25. Mirvis, P.H., Sales, A.L. \& Hackett, E.J. (2006). The implementation and adoption of new technology in organisations: the impact on work, people and culture. Human Resource Management, Nov. DOI: 10.1002hrm.3930300107. \{First published in Human Resource Management Spring 1991, 30(1), pp.113-139\}.

26. Nestle Nigeria PLC Annual Reports for 2015, 2016 and 2017

27. Noro, K. \& Imada, A. (1988). Participatory ergonomics. Philadelphia: Taylor \& Francis

28. Okafor, E.E. (2011). Youth unemployment and implications for stability of democracy in Nigeria. Journal of Sustainable Development in Africa, 13(1), March.

29. Presidential Enabling Business Environment Council (2018). Making Business Work Report in Nigeria-The Journey so far. Retrieved from www.easeofdoingbusiness.gov.ng on December 13, 2018

30. Schueller, S.M., Tomasino, K.N. and Mohr, D.C (2016). Integrating Human Support into Behavioural Intervention Technologies: The Efficiency Model of Support. Clinical Psychology: Science and Practice, 24(1), Nov 17.

31. Schwab, K. (2015). The Fourth Industrial Revolution: What It Means and How to Respond. Retrieved from https://www.foreignaffairs.com/articles/2015-12-12/fourth-industrial-revolution on December 12, 2018.

32. Shittu, (2018). Extracted from Vanguard newspapers vide www.vanguardngr.com on December 6, 2018

33. Society for Human Resource Management (2016). The New Talent Landscape- Recruiting Difficulty and skills shortages, being a report of the Society for Human Resource Management.

34. UBA PLC Annual Reports for 2015, 2016 and 20171

35. World Economic Forum (2016). The future of job report: Employment, Skills and Workforce Strategy for the Fourth Industrial Revolution, January 2016.Retrieved on Novem 31, 2018 from www.report.weforum.org/future-of-jobs-2016/

36. World Economic Forum (2018). Innovation with a purpose: the role of technology innovation in accelerating food systems transformation. Prepared in collaboration with McKinsey \& Company

37. XU, M., David, J.M. \& Kim, S. H. (2018). The Fourth Industrial Revolution: Opportunities and Challenges. International Journal of Financial Research, 9(2), 90-95. February. 